\title{
Bagasse-Based Desiccant Wheel Dehumidifier
}

\author{
H. Ramchurreetoo ${ }^{a}$, B. Rajkumarsingh ${ }^{b}$ \\ Received 17 June 2019, in revised form 27 August 2019 and accepted 27 August 2019
}

\begin{abstract}
Green desiccants are obtained from natural waste products like bagasse. They are fully biodegradable and cause no harm to the environment compared to chemical desiccants. A bagasse-based desiccant wheel dehumidifier that uses a green desiccant like sugarcane bagasse to remove humidity from air has been implemented and tested. Sugarcane bagasse was chosen as the main desiccant since it not only shows high adsorption properties but is also abundant in Mauritius and is much cheaper compared to other desiccants. The prototype was implemented and tested under various input parameters. A mathematical model was constructed to show how the dehumidification rate varies with airflow, desiccant wheel speed and bagasse thickness. It was found that dehumidification rate increases with an increase of the previously mentioned parameters. Another finding showed that as dehumidification rate increases, a higher regeneration rate for the desiccant is required. At maximum operating conditions, the dehum

idifier has a Coefficient of Performance of 0.0118 and a Moisture Removal Capacity of $2.06 \mathrm{~g} / \mathrm{min}$. It could also be deduced that at lower temperature, the prototype has a better efficiency. A controller was implemented and incorporated in the dehumidifier which responded well to different inlet air relative humidity and temperature.
\end{abstract}

Additional keywords: Desiccant Wheel Dehumidifier, Dehumidification, Sugarcane Bagasse.

\section{Introduction}

The quality of products in industries is affected if a proper humidity level is not maintained. Moreover, human beings tend to feel uncomfortable if the humidity level at a certain temperature is too high. High humidity tend to pose lots of problems in houses as it promotes the growth of moulds, dust mites and fungus thus leading to numerous infections and illnesses [1].

Two main types of dehumidifiers, namely Refrigeratorstyle dehumidifiers and Chemical absorbent (Desiccant) dehumidifiers [2] are used to solve humidity problems. The refrigerator type passes air over a cold coil containing compressed refrigerants, where water vapour condenses and falls into a tray. The air is then warmed and dry air is released back in the surroundings. The desiccant dehumidifier simply passes air over a desiccant material which absorbs water vapour and dries the air. It is most efficient in regions with low temperatures. The advantages of a desiccant dehumidifier is that it is cheaper to operate and uses less power than the refrigerator dehumidifier which requires a

a. Faculty of Engineering, University of Mauritius, Reduit, Mauritius, hewish007@gmail.com

b. Department of Electrical and Electronic

Engineering, University of Mauritius,

b.rajkumarsingh@uom.ac.mu compressor. The desiccants are available in cartridges that need to be discarded after use. The most commonly used one for large scale applications is the Desiccant Wheel Dehumidifier. The desiccant is stored in a large rotating wheel and air is passed through the wheel to remove water vapour.

Desiccant Wheel Dehumidifiers are made up of a desiccant wheel enclosed in a box like structure. A fan draws air through the wheel and the desiccant absorbs the water vapour from the air, hence achieving humidity control in an environment. To regenerate the wheel and dry the desiccant, another warm air stream is passed through it to remove the adsorbed vapour which is sent outside.

Most dehumidifiers use desiccants like silica gel which is a chemically produced substance. Although it is a very good adsorbent, silica gel is costly to replace and some are potentially cancerous if they come into contact with other chemicals like cobalt dichloride [3]. Furthermore, most dehumidifiers are expensive and have high power consumption. They are mostly plug and play type whereby the user has little control upon their internal setups. This restricts their use for a particular purpose in an unusual environment. In a world where we are talking of green energy and smart homes, currently available dehumidifiers are far from fulfilling the requirements to be classified as advanced, ecological and sustainable.

Rice husk blends that have been chemically treated were used as a green desiccant [4]. The absorbance of acid-treated, alkali-treated and bare rice husks blends were studied. Acid treated husk showed better absorbance. It was then compared with silica gel. Rice husk showed higher absorbance than silica gel and surpassed the silica-gel limit at 48 hours of exposure time. Moreover, rice husks have smaller regeneration periods than silica-gel. The study reveals that rice husk, a natural waste product can be used as desiccant.

Experimental investigations were carried out on newly designed desiccant wheels to analyse their performance. It was found that, higher regeneration air temperature increases dehumidification potentials. Rising air water content increases dehumidification capacity while maintaining dehumidification efficiency. In humid climates, desiccant wheel dehumidifiers are highly used [5].

The latest advance in desiccant-based dehumidification is the series regeneration. This design uses a cooling coil and a preheated coil. The desiccant wheel is placed in series with the cooling coil. Moisture transfer occurs with a single air stream unlike traditional ones which use two. The series wheel adsorb water vapour from the process air downstream of the cooling coil and then releases collected moisture upstream of that coil [6].

The moisture content of sugarcane bagasse is 51.5\%. By using a dryer, it is possible to reduce this moisture content [7].

$$
\begin{array}{r}
R \& D \text { Journal of the South African Institution of Mechanical Engineering 2019, 35, 31-37 } \\
\text { http://dx.doi.org/10.17159/2309-8988/2019/v35a4 }
\end{array}
$$

http://www.saimeche.org.za (open access) (C) SAIMechE All rights reserved. 
The Institute of Refrigeration in Paris suggests that air conditioning systems nowadays account for $15 \%$ of the world total energy consumption. Desiccant cooling systems have been developed as a more eco-friendly system to control temperature and humidity of air [8].

The energy effectiveness of desiccant wheels was studied and energy relations were developed for the power consumption and regeneration heat. By varying the regeneration temperatures and wheel speeds, it was observed that at $61.9^{\circ} \mathrm{C}$ and a wheel revolution of 21.2 revolutions per hour gave optimum results [9].

New techniques are being developed for regeneration of desiccant wheels. Heat conductive plates containing an expanded web of silica gel form the desiccant element. The silica gel absorbs moisture from incoming air. For regeneration of silica gel, a small ambient air stream is heated by a solar collector [10].

The aim of this work is to design and develop a revolutionary Desiccant Wheel Dehumidifier that uses an alternative green desiccant like bagasse which is a natural byproduct. Little is known about the adsorption properties of these desiccants. A research study has been carried out on the integration of bagasse as desiccant in the wheel. The most commonly available bagasse in Mauritius is sugarcane bagasse.

The main objectives were:

- To investigate the use of a green desiccant like bagasse to make the apparatus eco-friendly and sustainable.

- To design and build an all-purpose dehumidifier that can be used at home or in industry by just varying the size.

The paper is organized as follows. Section 2 outlines the methodology used to set up this dehumidifier. Experiments were carried out on bagasse to investigate its feasibility as an alternative desiccant. Based on available data, an adsorption model has been developed for the new desiccant. A complete conceptual design of the proposed system is made. Appropriate mechanical, electrical/ electronic and software design were then developed. Section 2 also describes the implementation process. It shows the various steps required to set up the prototype. Section 3 outlines the experimental results obtained. Based on these results, it was possible to derive an experimental adsorption model of the dehumidifier. Section 4 concludes this project and suggests possible further works.

\section{Methodology}

\subsection{Desiccant Selection}

Adsorption is when one element is held inside another by physical bonds on the internal surfaces. In the case of desiccants, adsorption takes place, i.e. the water vapour or moisture will form a film of adsorbent on the surface of the desiccant [11]. A desiccant is a hygroscopic material that reduces humidity from air and adsorb moisture. Hence a dry, moisture free surrounding is achieved [12]. A desiccant will adsorb water vapour from the air until its vapour pressure is same as that of the surroundings. "The strength of a desiccant is measured by its equilibrium vapour pressure that is the pressure of water vapour which is in equilibrium with the desiccant.” Desiccants are usually available in solid or liquid forms. The most common types of desiccants used for dehumidification are Montmorillonite-Clay, Silica-Gel, Molecular Sieve, Calcium-Oxide and Calcium-Sulphate [13].

Bagasse is a fibrous matter that is left when sugarcane is crushed to extract its juice. It is a dry pulpy residue. Sugarcane bagasse is the largest cellulose based agro industrial by-product left after sugarcane is crushed. In Mauritius, sugarcane production occupies a large portion of the economy, of which a lot of bagasse is produced as byproduct.

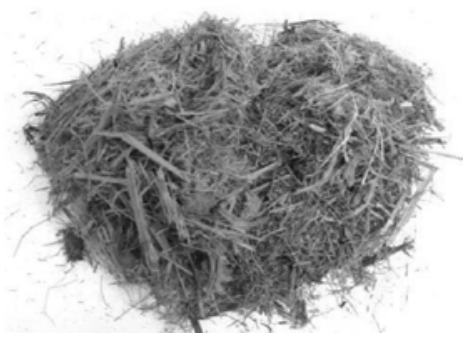

Figure 1 Sugarcane Bagasse

A chemical analysis of dried bagasse showed that it contained $45-55 \%$ cellulose, $20-25 \%$ hemicellulose, $18-24 \%$ Lignin, 1-4\% Ash and less than 1\% waxes. It usually has a moisture content of $40-60 \%$. Dried bagasse has good water adsorption properties [14]. The adsorption of water vapour by cellulosic materials at a constant temperature is categorized by sigmoid curves relating equilibrium moisture content and relative humidity. Sugarcane bagasse consists of $45-55 \%$ cellulose.

Tests have been performed on Sugarcane bagasse available from Omnicane Ltd in Mauritius to determine its water adsorption capacity. The bagasse was first dried in an oven at $800^{\circ} \mathrm{C}$ for 24 hours and its mass was measured. It was then soaked in distilled water for 1 minute, dried between absorbent papers and reweighed. The amount of water adsorbed per $100 \mathrm{~g}$ of bagasse was then calculated [15].

The results obtained were as follows:

Percentage relative humidity present before drying the

bagasse $=84 \%$

Mass of dried bagasse $=3.276 \mathrm{~g}$

Mass of soaked bagasse $=13.228 \mathrm{~g}$

Mass of water adsorbed $=9.952 \mathrm{~g}$

Mass of water adsorbed per $100 \mathrm{~g}$ of bagasse $=303.8 \mathrm{~g}$

"The sorption of water vapour by cellulosic materials at a constant temperature is categorized by sigmoid curves relating equilibrium moisture contents and relative humidity. Adsorption and desorption of water vapour by cellulosic materials at constant temperature result in isotherms taking sigmoid shapes. In thermodynamics analysis of these isotherms, decrease in Gibbs free energy of adsorbed or desorbed water is [16]:"

$\Delta G=\frac{-R T}{M} \ln \left[\frac{R H}{100}\right]$

where

$M$ - Molecular weight of water, $\mathrm{g} / \mathrm{mol}$

$R$ - Universal gas constant, $\mathrm{J} / \mathrm{mol} . \mathrm{K}$ 


\section{$T$ - Absolute Temperature, $\mathrm{K}$}

RH - Relative Humidity, \%

Let $m$ be moisture content expressed as a fraction of oven dry weight, $m_{s}$ be fibre saturation point, i.e. moisture content of material for which $\Delta G=0$ i.e. $R H=100 \%$

Let $\Delta G o$ be an estimate of $\Delta G$ as $R H$ approaches zero.

Assume, $m_{s}=m_{v}$ at $\Delta G=1$ and according to Stamm and Loughborough [17], a model to consider is:

$\left.\Delta G=(\Delta G o)^{\left(1-m / m_{v}\right.}\right)$

Substitute (2) in (1).

The desorption isotherm is

$$
\frac{R H}{100}=\exp \left(-\frac{M}{R T} \cdot(\Delta G o)^{\left(1-\frac{m}{m_{v}}\right)}\right.
$$

Since sugarcane bagasse consists of $45-55 \%$ cellulose, it can be used to model the adsorption and desorption isotherm of bagasse.

Assume,

$\Delta G o=47 \mathrm{cal} / \mathrm{g}$

$m_{v}=0.50$ since wet milled bagasse has moisture content of $50 \%$ [7]

$\frac{M}{R T}=0.0304$ at $T=298 \mathrm{~K}$

Assuming no hysteresis losses during adsorption, (4) has been derived to be used as the adsorption isotherm of bagasse.

$\frac{R H}{100}=\exp \left(-0.0304(47)^{\left(1-\frac{m}{0.5}\right)}\right)$

By plotting (4), figure 2 is obtained.

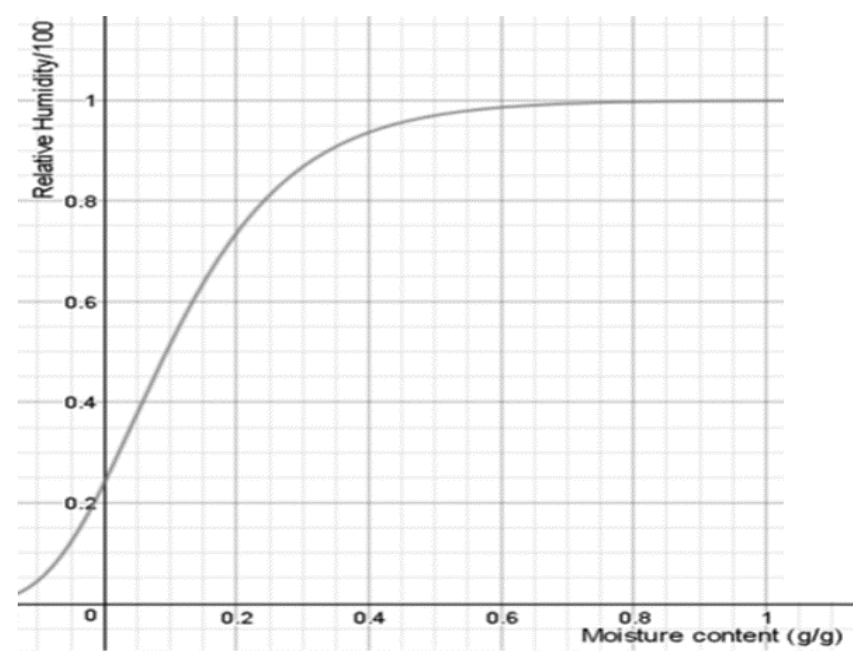

Figure 2 Relative humidity vs moisture content.

Figure 2 does not pass through the origin since a finite value was introduced in equation 3 for $\Delta G o$ as relative humidity approaches zero. In practice, when $R H=0, m=0$.

\subsection{Experimental Setup}

The bagasse-based desiccant wheel dehumidifier is expected to remove humidity from air and automatically bring it to the desired value depending on its application area. The dehumidifier uses two processes namely dehumidification and regeneration as shown in figure 3 .

The prototype consists of a main desiccant wheel which rotates about its axis by a motor. A fan passes air from the surroundings into the desiccant wheel which contains the desiccant bagasse. The relative humidity of the inlet air stream is measured using a humidity sensor. While the air stream comes into contact with the desiccant, it gives off water vapour to the desiccant's surface. The outlet air stream has a lower relative humidity. The latter is measured using another humidity sensor and it is compared to the desired set value. Based on the desiccant wheel speed, dehumidification fan speed and regeneration fan speed inputs, the prototype automatically adjusts its own parameters to ensure the most effective dehumidification process. This is done by a microcontroller. At the same time, another fan generates a smaller air stream that is heated by a heater and passed through a quarter of the desiccant wheel from the other side. This hot air stream passes through the desiccant and causes it to give its moisture to the hot air. This hot stream is carried outside the room through pipes. Regeneration of the desiccant is achieved.

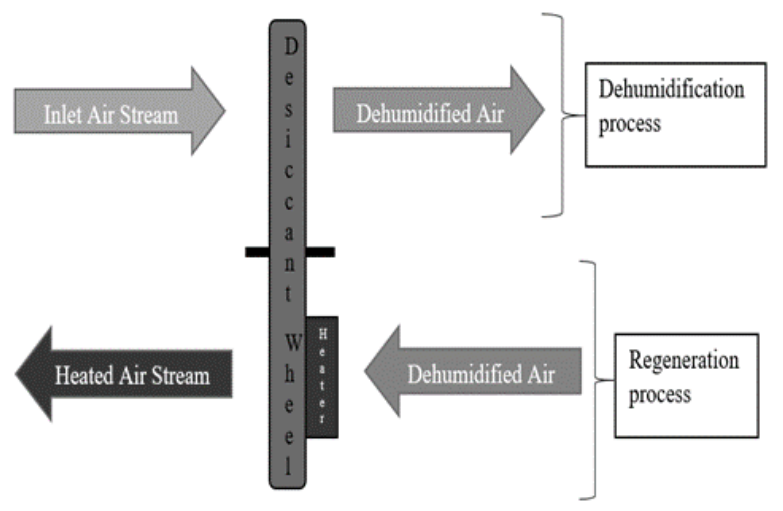

Figure 3 Desiccant wheel dehumidification and regeneration processes.

The rate of dehumidification is a factor of multiple parameters namely intake temperature, intake relative humidity, desiccant wheel rotational speed, air flow generated by fans, thickness of desiccant in the wheel and surface area provided by desiccant. By varying these parameters it is possible to alter the rate of dehumidification. In this dehumidifier, only four parameters were varied for experimental purposes, namely desiccant wheel rotational speed, dehumidification air flow, regeneration airflow and thickness of desiccant. But in the final prototype, three parameters were adjusted namely the desiccant wheel speed, dehumidification fan airflow and regeneration fan airflow. The intake relative humidity is the humidity in the room. For experimental purposes, it was raised to around $90 \%$ using a mini humidifier and then dehumidification was carried out.

The regeneration process is carried out carefully as bagasse is a combustible material at high temperatures. Effective drying temperature for bagasse is $80-105^{\circ} \mathrm{C}$ in an oven. But since bagasse is be used inside the prototype, it is better to limit the temperature to about $70^{\circ} \mathrm{C}$ for safety purposes. An aluminium foil pipe is used to drive the hotter air outside the room.

Figure 4 represents a 3D concept of the arrangement of the main components of desiccant.

Several tests were performed to determine the best range of air flows and speed of a desiccant wheel for different inlet

http://www.saimeche.org.za (open access) (c) SAIMechE All rights reserved. 
air relative humidity. The proposed experiment was as followed:

\section{Set-up}

- A mini humidifier produces desired process (inlet) air relative humidity.

- The desiccant wheel is fitted with a certain mass of bagasse and thin strips is used inside the wheel to vary the thickness of the desiccant in the wheel between $10 \mathrm{~cm}$ and $20 \mathrm{~cm}$.

- $\quad$ Range of wheel rotation is chosen between $0 \mathrm{rpm}$ and $20 \mathrm{rpm}$.

- Range of air flow in dehumidification fan can be chosen between 0 to $1360 \mathrm{~m}^{3} / \mathrm{h}$. A hand held anemometer is used to measure air flow.

- Range of air flow in regeneration fan can be chosen between 0 to $425 \mathrm{~m}^{3} / \mathrm{h}$.

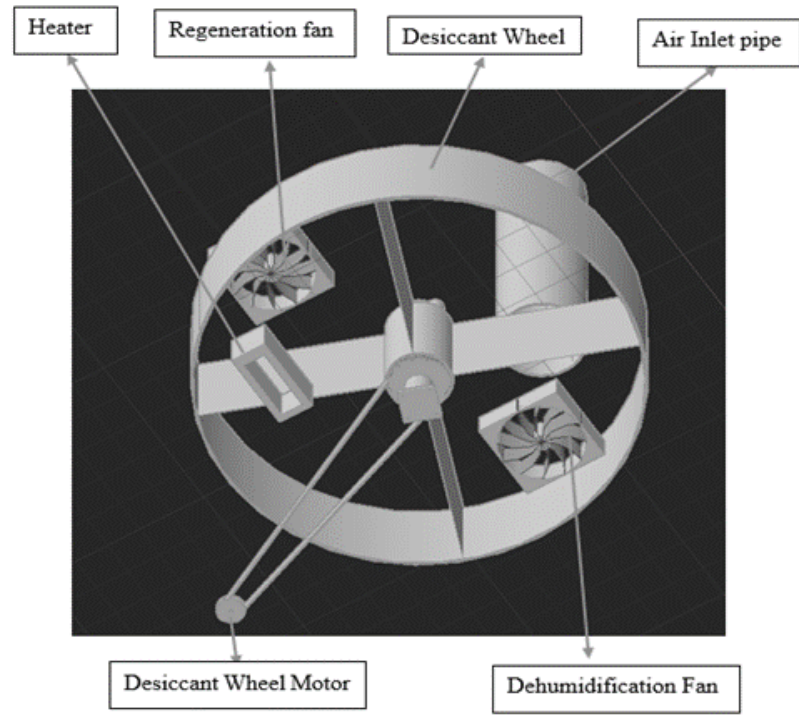

Figure 4 3D concept of desiccant wheel.

II. Experiment to determine wheel revolution speed and dehumidification air flow rate.

- $\quad$ Plot graph of temperature against time and output \% relative humidity against time.

- Manipulate the air flow in dehumidification fan and repeat steps above.

- Increase the wheel revolution speed 10 and $20 \mathrm{rpm}$ and for each interval repeat step above.

Repeat the whole experiment by decreasing bagasse thickness to $10 \mathrm{~cm}$. Compare the results obtained to see if increasing desiccant thickness increases moisture removal capacity and decreases time to reach steady state.

III. Experiment to determine regeneration air flow

- Turn ON dehumidification fan to maximum speed.

- $\quad$ Set regeneration fan at max speed, the heater ON and wheel rotation to $5 \mathrm{rpm}$.

- Measure the inlet and outlet air relative humidity, and outlet air temperature.

- A graph of output air relative humidity against time is plotted until steady state is reached.

- Manipulate the air flow of the regeneration fan and repeat steps above.

- Repeat step 5 for wheel rotations at $10 \mathrm{rpm}$ and $20 \mathrm{rpm}$.
IV. Analysis

- $\quad$ For each experiment in II, the best possible parameters that help achieve steady state the in shortest time is measured.

- For each experiment in III, the best parameter that removes maximum moisture from the bagasse is measured.

\subsection{Mechanical Setup}

The structure of the frame is designed taking into consideration the locations of different components like drive mechanism, heaters, fans, electronics and motors. Careful selection of material was also made. Fans were chosen so that they are able to process a certain amount of air in a given time to optimize the performance of the prototype. The desiccant wheel, shaft and drive mechanism were designed by performing appropriate calculations to ensure that they function without excessive mechanical wear and distortion. Figure 5 shows the prototype design and figure 7 the completed prototype.

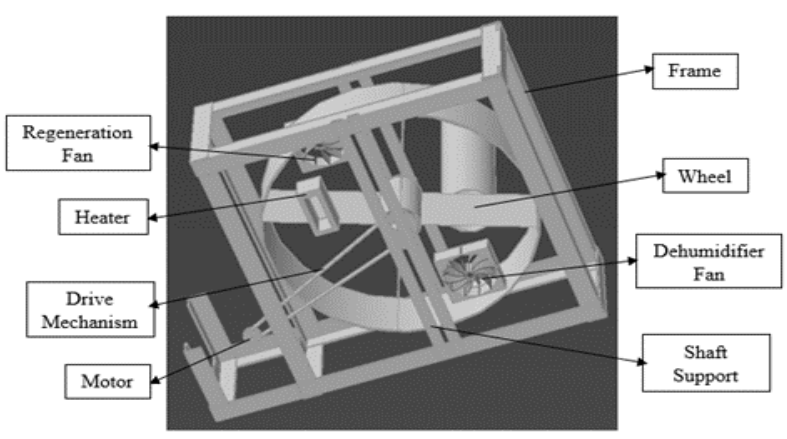

Figure 5 Prototype design

Figure 6 gives the dimensions of the desiccant wheel and pulley.

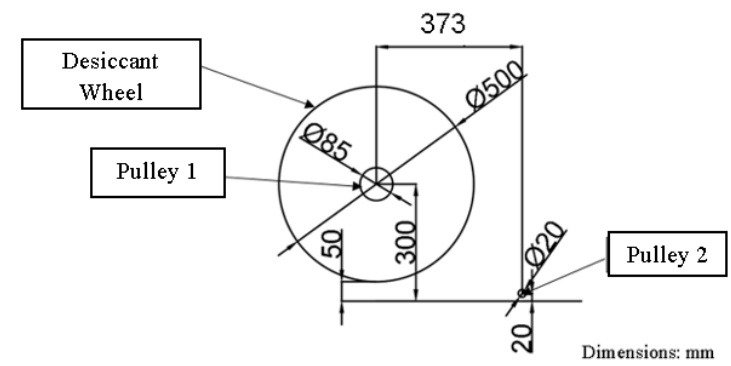

Figure 6 Desiccant wheel and pulley experiments.

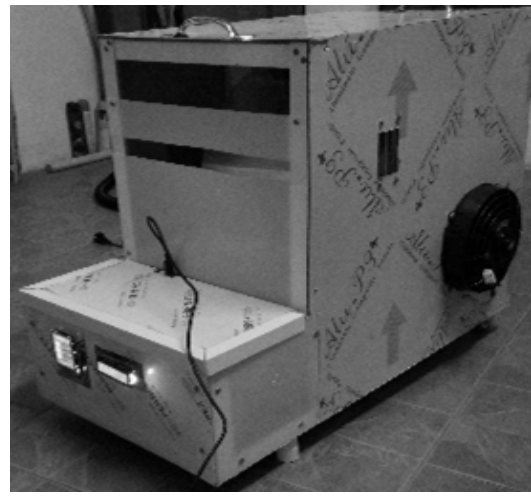

Figure 7 Completed prototype.

$R \&$ D Journal of the South African Institution of Mechanical Engineering 2019, 35, 31-37 http://dx.doi.org/10.17159/2309-8988/2019/v35a4

http://www.saimeche.org.za (open access) (c) SAIMechE All rights reserved. 


\section{Experiments}

In order to determine the best dehumidification rates, a model has to be developed. In this section, an empirical model is derived based on the experiments.

The dehumidification rate is a function of bagasse thickness, wheel speed and dehumidification fan (DF) airflow. The dehumidification fan airflow speeds used are $4.2 \mathrm{~m} / \mathrm{s}$ (DF low), $4.7 \mathrm{~m} / \mathrm{s}$ (DF mid) and $5.2 \mathrm{~m} / \mathrm{s}$ (DF high). The air inlet has a diameter of $120 \mathrm{~mm}$. Therefore, the airflow is given by:

Dehumidification Airflow $=$ $\pi(60)\left(0.060^{2}\right)$ (airflow speed) $\mathrm{m}^{3} / \mathrm{min}$

where the radius of air inlet is $0.060 \mathrm{~m}$.

The regeneration process is a function of wheel speed and regeneration airflow. The regeneration fan air speeds are 1.8 $\mathrm{m} / \mathrm{s}$ (low), $1.9 \mathrm{~m} / \mathrm{s}$ (mid) and $2.0 \mathrm{~m} / \mathrm{s}$ (high). The air inlet is rectangular with dimensions $50 \mathrm{~mm} \times 70 \mathrm{~mm}$. Therefore airflow is given by:

Regeneration airflow $=$ (60)(0.050)(0.070)(airflow speed) $\mathrm{m}^{3} / \mathrm{min}$

The variation in relative humidity against time was first studied under various wheel speeds and airflow combinations. The dehumidification rates for each combination were then determined from the gradients of the graphs of relative humidity against time. Then, the graphs for dehumidification rate against airflow were plotted as shown in figure 8 and figure 9.

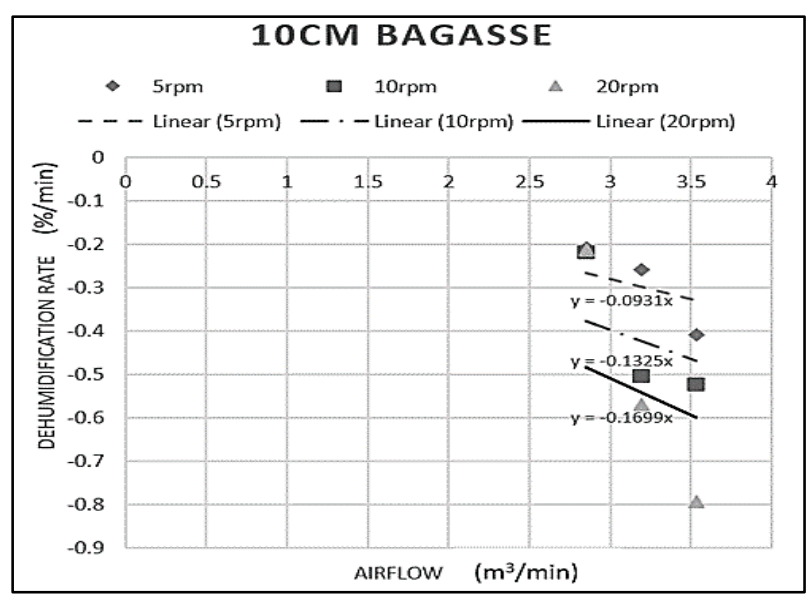

Figure 8 Graph of dehumidification-10 $\mathrm{cm}$ bagasse

\subsubsection{Results}

The experimental observations that were made are as follows:

- Increasing the bagasse thickness increases dehumidification rate.

- As the dehumidification airflow increases, dehumidification rate increases. This is applicable at all wheel speeds.

- When dehumidification airflow is low, input and output temperatures are almost the same. As the air flow is increased, a small increase in output air temperature is measured.

- For the same dehumidification airflow, higher wheel speed yields a higher dehumidification rate. It is better to regenerate the desiccant at the same as time as the dehumidification process to ensure maximum adsorption process. It is observed that increasing the regeneration airflow at a particular wheel speed, increases regeneration rate.

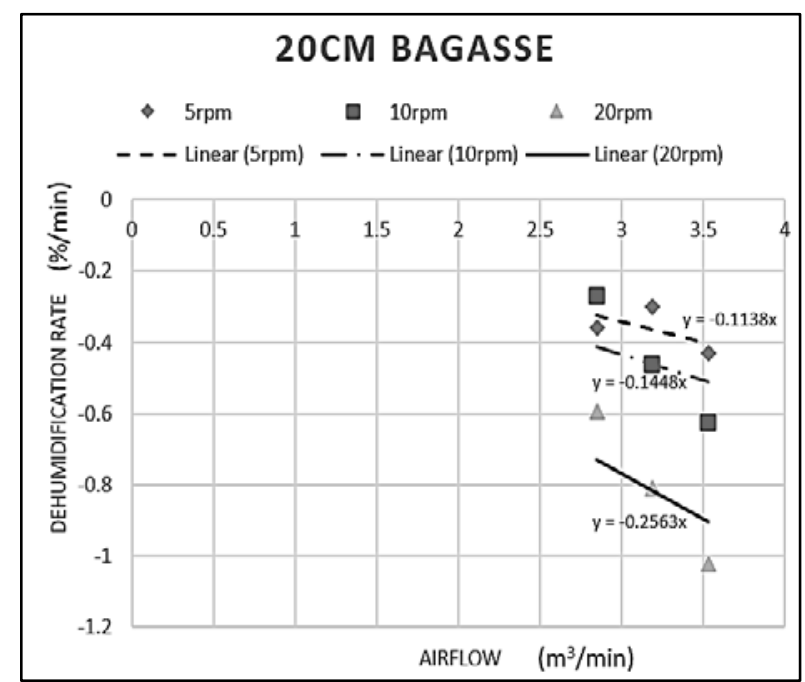

Figure 9 Graph of dehumidification-20 cm bagasse

A graph of dehumidification rate against regeneration rate is plotted as shown in figure 9 .

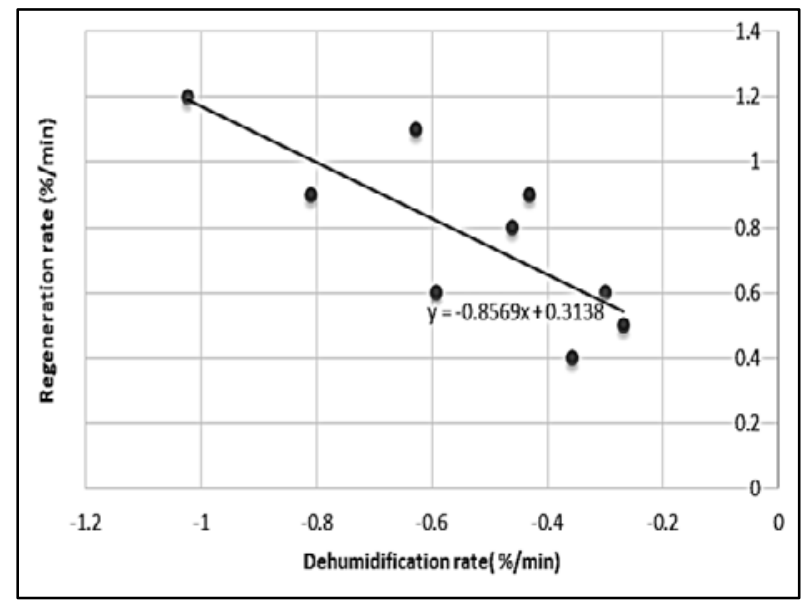

Figure 10 Regeneration rate vs dehumidification rate

Eighteen data sets were collected were analysed by multiple linear regression in Excel. The aim was to determine how dehumidification rate (DR) varies with wheel speed (WS), dehumidification airflow (DA) and bagasse thickness (BT). Table 1 gives the statistical values.

Table 1 Statistical values

\begin{tabular}{lll}
\hline R-square & 0.8298 & \\
\hline & Coefficients & P-value \\
\hline Intercept & 1.5085 & 0.0002 \\
Wheel Speed (rpm) & -0.0227 & 0.0001 \\
Dehumidification Airflow & & \\
$\left(\mathrm{m}^{3} / \mathrm{min}\right)$ & -0.4777 & 0.0001 \\
Bagasse Thickness (cm) & -0.0131 & 0.0197 \\
\hline
\end{tabular}

Equation (7) is the regression model equation obtained. 
$D R=1.5085-0.02272(W S)-0.4777(D A)-$ $0.0131(B T)$

The R-square value is 0.8298 which shows that the model fits the data as it is close to 1 . The P-values for all the independent variables are less than 0.05 meaning that they have a significant effect on the output relative humidity. It is deduced that wheel speed and dehumidification airflow has a greater effect on the dehumidification rate due to their smaller P-values.

The efficiency of a dehumidifier is called the coefficient of performance. The total coefficient of performance, COP, is the ratio of process air enthalpy change to the energy provided for regeneration process [18]. At maximum operating conditions, the coefficient of performance of this dehumidifier is calculated to be 0.0118 The Moisture Removal Capacity, MRC, is $2.0579 \mathrm{~g} / \mathrm{min}$.

The electrical efficiency of the dehumidifier is the ratio of volume of water vapour removed to power used per $\mathrm{kWh}$. Efficiency $=124 / 0.355=349 \mathrm{~cm}^{3} / \mathrm{kWh}$. By comparing cost and efficiency, this dehumidifier has an efficiency of $0.349 \mathrm{l} / \mathrm{kWh}$ but a cost approximately five times less than other desiccant wheel dehumidifiers.

\subsubsection{Desiccant Dehumidifier Comparison}

The COP of silica gel is approximately 0.12 , which is ten times better than that of this dehumidifier. The MRC of silica gel is $5.6 \mathrm{~g} / \mathrm{min}$ which is 2.5 times greater than bagasse. However the bagasse dehumidifier's performance can be improved. This can be achieved by considering:

- Process and regeneration inlet temperatures: By decreasing inlet process temperature, the adsorption potential of bagasse increases, hence increasing MRC and COP. By increasing regeneration temperature, more adsorbed moisture is removed from the bagasse and hence the MRC at process inlet increases.

- Wheel speed: Increasing wheel speed up to a certain optimal one can increase MRC. This has been observed as speed increases from $5 \mathrm{rpm}$ to $20 \mathrm{rpm}$.

- Mass flow rates: Increasing mass flow rates of process and regenerate inlet air improve COP as more humid air is passed through the desiccant wheel.

The prototype is expected to have a minimal impact on the environment. The lifespan of bagasse is approximately 6 months. After this period, it starts to degrade and has to be replaced to ensure that the dehumidifier's efficiency is maintained. The desiccant used is bio-degradable and easily disposed-off after maintenance. Sugarcane bagasse can be procured at a cost of about 4 USD/ton. Contrary to silica gel and other synthetic desiccants, bagasse is a natural product which will not cause harm to the environment. As for the dehumidifier, all the construction materials like aluminium and alucobond can be recycled. This makes the prototype very sustainable.

\section{Conclusion}

High humidity is a major concern as it causes several health problems and deterioration of goods. Most dehumidifiers use desiccants like silica gel which is a chemically produced substance. It is a very good adsorbent but silica gel is costly to replace and some are potentially cancerous if it comes into contact with other chemicals. The aim of this work was to design and characterise a desiccant wheel dehumidifier that would be used to investigate the use of green desiccant materials like sugarcane bagasse. The prototype was designed in various stages starting with a concept followed by detailed design of the mechanical parts, electrical parts and software control.

Some of the major findings are that increasing the wheel speed, dehumidification airflow or bagasse thickness increases the rate of dehumidification. When dehumidification rate increases, it is required to increase the regeneration rate. Finally, the coefficient of performance and moisture removal capacity of the dehumidifier were calculated to compare it to a silica gel desiccant wheel dehumidifier. The performance was not as high as that of silica gel dehumidifier but suggestions have been made to improve the efficiency.

It can be concluded that the green desiccant bagasse can be incorporated in desiccant wheel dehumidifiers. This revolutionary concept will definitely help in designing more environment-friendly dehumidifiers.

\section{References}

[1] Disadvantages of excessive low and high humidity, Appxis, 2018. URL www.appxis.com/information/ disadvantages-excessive-low-and-high-humidity

[2] All the different types of dehumidifiers and how to tell the difference, Good Air Geeks, 2018. URL www.goodairgeeks.com/types-dehumidifiers/

[3] Blue Indicating Silica Gel a Hazardous, Potentially Carcinogenic Pollutant, Cobaltchloride.net, 2009. URL www.cobaltchloride.net/

[4] Z. Emdadi, N. Asim, M. Ambar Yarmo, M. Ebadi, M. Mohammad and K. Sopian. Chemically treated rice husk blends as green desiccant materials for industrial application. Chemical Engineering \& Technology, 40(9):1619-1629, 2017.

[5] E. Tiwari. Design and fabrication of desiccant wheel dehumidifier. International Journal of Advanced Research in Mechanical Engineering \& Technology, 1:1-10, 2015.

[6] Advances in desiccant-based dehumidification. Trane Engineers Newsletter, 34:4, 2005.

[7] J. Sudhakar and P. Vijay. Control of moisture content in bagasse by using bagasse dryer. International Journal of Engineering Trends and Technology, 4(5):1331-1333, 2013.

[8] M. Sahlot and S. B. Riffat. Desiccant cooling systems: a review. International Journal of Low-Carbon Technologies, 11(4):489-505, 2015.

[9] M. Ali Mandegari, H. Pahlavanzadeh and S. Farzad. Energy approach analysis of desiccant wheel operation. Energy Systems, 5(3):551-569, 2014.

[10]D. Gidaspow, Z. Lavan and M. Onischak. Thermally regenerative desiccant element. United State Patent, US4341539A, 1982.

[11]T. Dywer. Module 71: Liquid desiccants for dehumidification in building air conditioning systems. Chartered Institution of Building Services Engineers Journal, 2014.

http://www.saimeche.org.za (open access) (C) SAIMechE All rights reserved. 
[12] Delta Absorbants. What is a Desiccant?, 2013. URL www.deltaadsorbents.com/Blog/Post/6/what-is-adesiccant.

[13] SorbentSystems, Desiccant Types, Sorbentsystems.com, 2013. URL: Www.sorbentsystems.com/ desiccants_types.html.

[14] V. Mittal and S. Sinha. Mechanical, thermal, and water absorption properties of wheat straw/bagasse-reinforced epoxy blended composites. Advances in Polymer Technology, 37(7):2497-2503, 2017.

[15]R. Wirawan, S. M. Sapuan, R. Yunus and K. Abdan. Density and water absorption of sugarcane bagasse-filled poly (vinyl chloride) composites. Polymers and Polymer Composites, 20(7):659-664, 2012.

[16]R. M. Nelson. A model for sorption of water vapor by cellulosic materials. Wood and Fibre Science, 15(1):822, 2007.

[17]A. J. Stamm and W. K. Loughborough. Thermodynamics of the sweeling of wood. The Journal of Physical Chemistry, 39(1):121-132, 1935.

[18]M. Kanoğlu, M. Ö. Çarpınlığlu and M. Yıldırım. Energy and exergy analyses of an experimental opencycle desiccant cooling system. Applied Thermal Engineering, 24(5-6):919-932, 2004. 